\title{
THE CHALLENGES OF INDUSTRY 4.0 FOR SMALL AND MEDIUM ENTERPRISES IN POLAND AND SLOVAKIA
}

doi: 10.2478/cqpi-2019-0020

Date of submission of the article to the Editor: 04/05/2019

Date of acceptance of the article by the Editor: 02/06/2019

Robert Ulewicz ${ }^{1}$ - orcid id: 0000-0002-5694-4284

Franitisek Novy ${ }^{2}$ - orcid id: 0000-0002-7527-5020

Kanchana Sethanan ${ }^{3}$ - orcid id:

${ }^{1}$ Czestochowa University of Technology- Poland

2University of Zilina - Slovakia

${ }^{3}$ Khon Kaen University - Thailand

Abstract: In the paper an analysis of the state of preparation of small and mediumsized enterprises in the metal industry in Poland and Slovakia was presented. Based on the conducted surveys, the challenges of industry 4.0, which will have to be met by small and medium enterprises, have been identified. Opportunities and threats for enterprises from the SME sector have been also defined. It was found that the biggest threats was lack of capital and lack of appropriate specialists, as well as high costs of staff preparation. Opportunities for enterprises are increased productivity and productivity, faster response to changes to customer requirements.

Keywords: Industry 4.0, SME, smart factory, metal industry)

\section{INTRODUCTION}

In recent decades, producers and suppliers of goods and services have improved the quality of their organizations through the use of innovative technologies (Deloitte, 2015). This is because the industry is undergoing transformation and evolution toward complete digitization and the intelligence of production processes to ensure high efficiency (Wiśniewska-Sałek, 2018). To achieve these goals, it is necessary to implement new technologies for the automation of industrial processes. Industry 4.0 is a concept that permanently changes the model of functioning of enterprises in the industrial sector. Production management processes in the current shape will undergo significant reorganization. Huge amounts of data generated by control systems, currently used mostly to monitor the state of technological processes, in large enterprises and in the future also in small and medium-sized companies will allow to predict their behavior, quality parameters of products, and enable global production control. Machine to Machine communication technologies, the use of the Industrial Internet of Things (IloT), as well as advanced information processing methods will be a key factor in digital transformation. Integration of individual elements of business 
processes will allow for quick response to market demand and inclusion of suppliers and customers in the production, sales and distribution process (Marilungo et al. 2017). Factories will become intelligent, production lines will automatically modify work parameters, devices will exchange information between them, quickly and effectively modify the configuration of products. Production will become more flexible and manufacturers will be able to implement more complex orders faster and cheaper than before. The entire transformation of industry to the digital 4.0 model will also be a significant change from the point of view of the organization and processes. The role of man will change significantly. We already have examples of companies co-managed by artificial intelligence. The employee no longer takes key decisions and ceases to be responsible for monitoring, controlling and coordinating production processes. The problem of defining a new role for a human being in the digital system will appear and it will force him to acquire new capabilities in the digital field (programming the process, defining procedures and passing the executive and optimization functions to the machines). Already today, changes in the process of recruiting employees are noticeable by introducing the required digital skills position in the curriculum vitae. The change in the perception of a man in the production system will be difficult and is associated with a different degree of digital competence resulting from generational differences (Weyer, et. al 2015, Kovács, et al. 2017).

Industry 4.0 is a process that is revolutionizing the production sector, the way plants operate and the use of products. Thanks to the use of robotics, advanced IT tools, data analysis and deepening cooperation between people and devices in the future, factories will operate $30 \%$ faster and their efficiency will increase by at least $25 \%$. The question arises whether small and medium enterprises are prepared for the revolution 4.0 and what opportunities and threats result from the transformation of 4.0 for the sector of small and medium enterprises (Thoben et al. 2017; Ślusarczyk, 2018, Malindzak et al. 2017).

\section{Industry 4.0 in Poland and Slovakia}

According to statistical data published by Eurostat, five industries generate, on average, $52 \%$ of gross value added in industrial production in Poland and they are: production of food, beverages and tobacco products, processing of metal products, production of motor vehicles, production of rubber and plastic products and furniture production. In these industries, $50 \%$ of employees working togeter in industrial production were employed. The share of personnel costs in the total production costs was the largest in the metal goods industry in Poland and Slovakia. Analyzing the cost of man-hours with the cost of machine hours, we observe a tendency to align with the cost of machine hours. As a consequence, it will necessitate the industry's concept of Industry 4.0. Figure 1 shows changes in labor costs and man-hour costs. The analysis shows that the costs may be even with the current trend between 2021-2023, which will be the culmination point in the implementation of the industry concept 4.0.

At present in Poland and Slovakia we can observe a tendency to bring this type of production to countries with much lower production costs, mainly China and India. Despite the additional costs associated with transport logistics, the transfer of production is more profitable than on-site production. It should be emphasized that China also sees great opportunities in the Industry 4.0 concept. China is currently the largest recipient of industrial robots in the world and consistently implements the assumptions of the plan "Made in China 2025", which is also to be a response to the 
problem of aging population and the future lack of manpower. When comparing system solutions in Poland and Slovakia with similar solutions in Germany, France or China, it should be stated that there are no solutions dedicated to the SME sector.

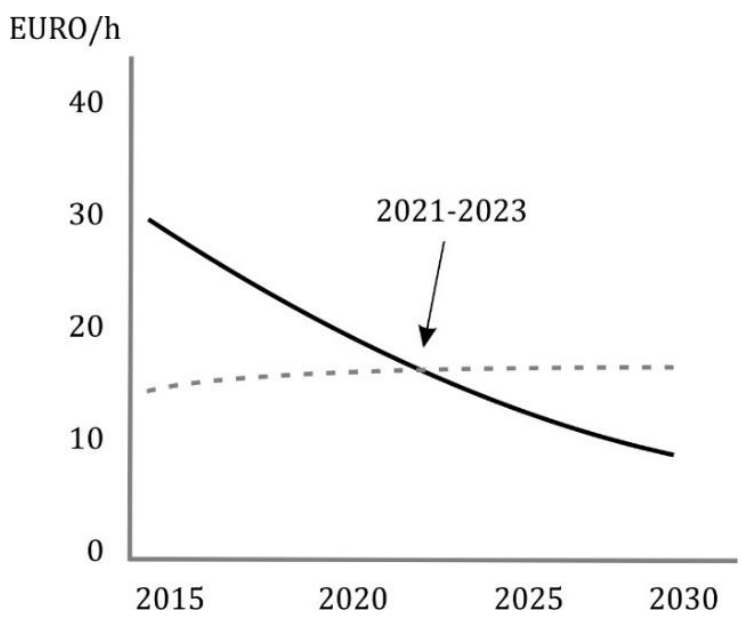

Fig. 1. Comparison of labor-hour and machine-hour labor costs in the metal products industry in Poland and Slovakia

IFR estimates that 10538 industrial robots were delivered to the CEE market last year (nearly $36 \%$ increase compared to 2016 ), and the total number of robots working in the region at the end of 2017 is 52863 (all of Europe: nearly 498000 ). Percentage change in sales in individual CEE countries, Hungary: $+245 \%$ (in total 2470 robots delivered), Russia + 99\% (711 robots), Czech Republic: $+47 \%$ (2893 robots), Poland: $+16 \%$ (1891 robots), Romania : $-19 \%$ (634 robots), Slovakia: $-31 \%$ (1203 works). The robotic density in the European processing industry is 106 units per 10000 employees (world average: 85). The leader in Europe is Germany: 322, in Poland it is 36 robots per 10000 employees. For CEE countries, the robotic density for Slovakia is 151, Czech Republic 119, Hungary 78, Romania 18 and Russia 4 units per 10000 employees. Considering the use of robots in the branches of industry, the automotive industry is at the first place in Europe, followed by metal, plastics and chemical products. The presented data indicate a long-term trend of increasing the share of robot use in industry. On the basis of literature studies and own research, it can be assumed that the degree of preparation of enterprises in Poland and Slovakia for revolution 4.0 is not explicit. There are many companies that are leaders not only on the domestic market but also international. However, this applies mainly to large enterprises or innovative enterprises. In the area of small and medium enterprises in the metal processing industry, the degree of preparation for system changes related to Industy 4.0 is very small. The reasons for this are, among others, lower labor costs compared to machine-hour costs, and above all a lack of capital, which is actually an obstacle that can not be overcome for companies from the SME sector (Gubbi et al. 2013; Fallera C., et al 2015). Another problem is the availability of appropriate specialists in the scale of the whole country, which puts a challenge before the higher education system, because the new industry will require different competences than the current one (Rosak-Szyrocka et al. 2016; Nitkiewicz eta al. 2018; Hariharasudan 2018). Another problem is the lack of substantive support. At present, public entities are not institutionally and competently adapted to meet the requirements resulting from the concept of industry 4.0, i.e. cooperation with the private sector, consisting, among other things, in the coordination 
of public and private activities, or the possibility of financing tasks related to industry 4.0 by the public sector. There are no instruments disseminating knowledge and skills necessary for functioning in the realities of industry 4.0. We need dedicated support mechanisms for companies that want to invest in new solutions: loT, Al, robotization, $5 G$ communication, machine learning, blockchain, artificial intelligence, big data, Internet of things and industrial Internet, incremental production, augmented reality/virtual reality, simulations and modeling, 3D imaging, cloud computing, mass data processing, high-performance computing systems (HPC), robots and autonomous systems. This may mean, on the one hand, access to competitive financing on the market, and on the other hand to the latest global achievements as practical as well as scientific and research (Herrmann et al. 2014; Pedersen et al.2016; Pereira et al. 2017). Transformation 4.0 is a big challenge for Small and Medium-sized enterprises not only in the aspect of implementation of modern technology but also in the management and quality assurance. Transformation 4.0 should force the creating learning organization in particular in the area of SME's (Anttila and Jussila, 2018).

\section{Test result}

The research was based on surveys supported by a direct interview. This approach was associated with the need to explain the descriptive concepts contained in the survey. For over half of the enterprises surveyed in the SME sector in Poland and Slovakia, the terms used were misunderstood or imprecisely interpreted. It also indicates a large gap in the preparation of the SME sector for transformation 4.0. The selection of the sample was purposeful, non-probabilistic. 51 enterprises from the sector of processing of metal products (38 from Poland and 13 from Slovakia) were qualified for the research, which constituted only $30 \%$ of the research sample. Only enterprises that knew the basic composition of Industry 4.0 were qualified for the study. The very number of enterprises not qualified for further research indicates the lack of knowledge in the field of industrial fundamentals 4.0.

One of the key questions was to determine the level of company digitalization. In the field of digitalization, very similar results for Polish enterprises were obtained at the level of $19 \%$ and for Slovak companies at the level of $22 \%$. However, it should be emphasized that the digitalisation concerned mostly communication channels and cooperation with suppliers and clients (Fig.2).

The obtained results confirm the low level of digitalization in the field of horizontal integration, i.e. integration related to the processes implemented for Polish enterprises amounted to $14 \%$ and for Slovak enterprises $10 \%$. In the field of vertical integration, the situation is much better because it concerns contacts with customers and suppliers who often enforce the digitization of processes. Analyzing further the problem of horizontal and vertical integration, questions were asked regarding the use of systems:

- ERP - Enterprise Resource Planning

- MES - Manufacturing Execution Systems

- APS - Advanced Planning and Scheduling

- WMS - Warehouse Management System

- $\mathrm{BI}$ - Business Intelligence

- PLM - Product Lifecycle Management

The obtained results are shown in Figure 3. In enterprises, the most commonly used applications are EPR and MES as well as WMS. 


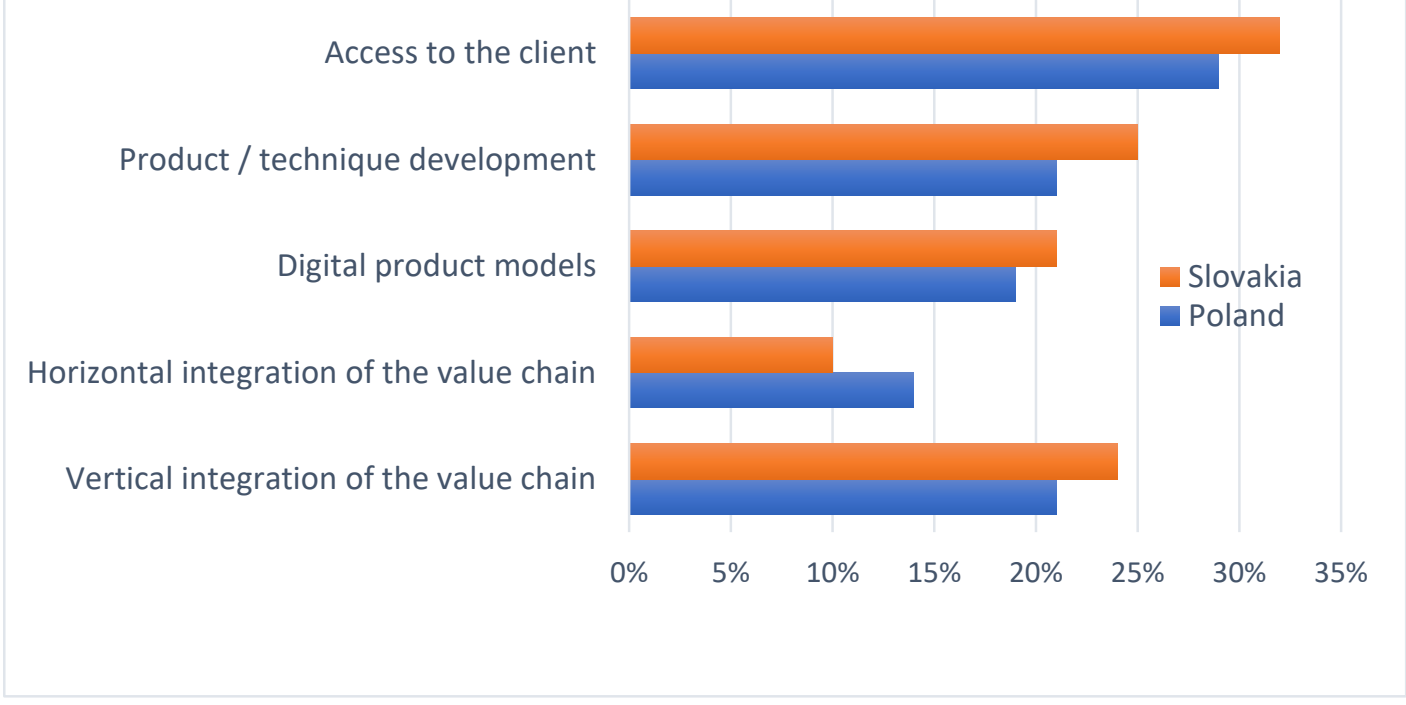

Fig. 2. The level of digitization of individual areas for a research sample from Poland and Slovakia

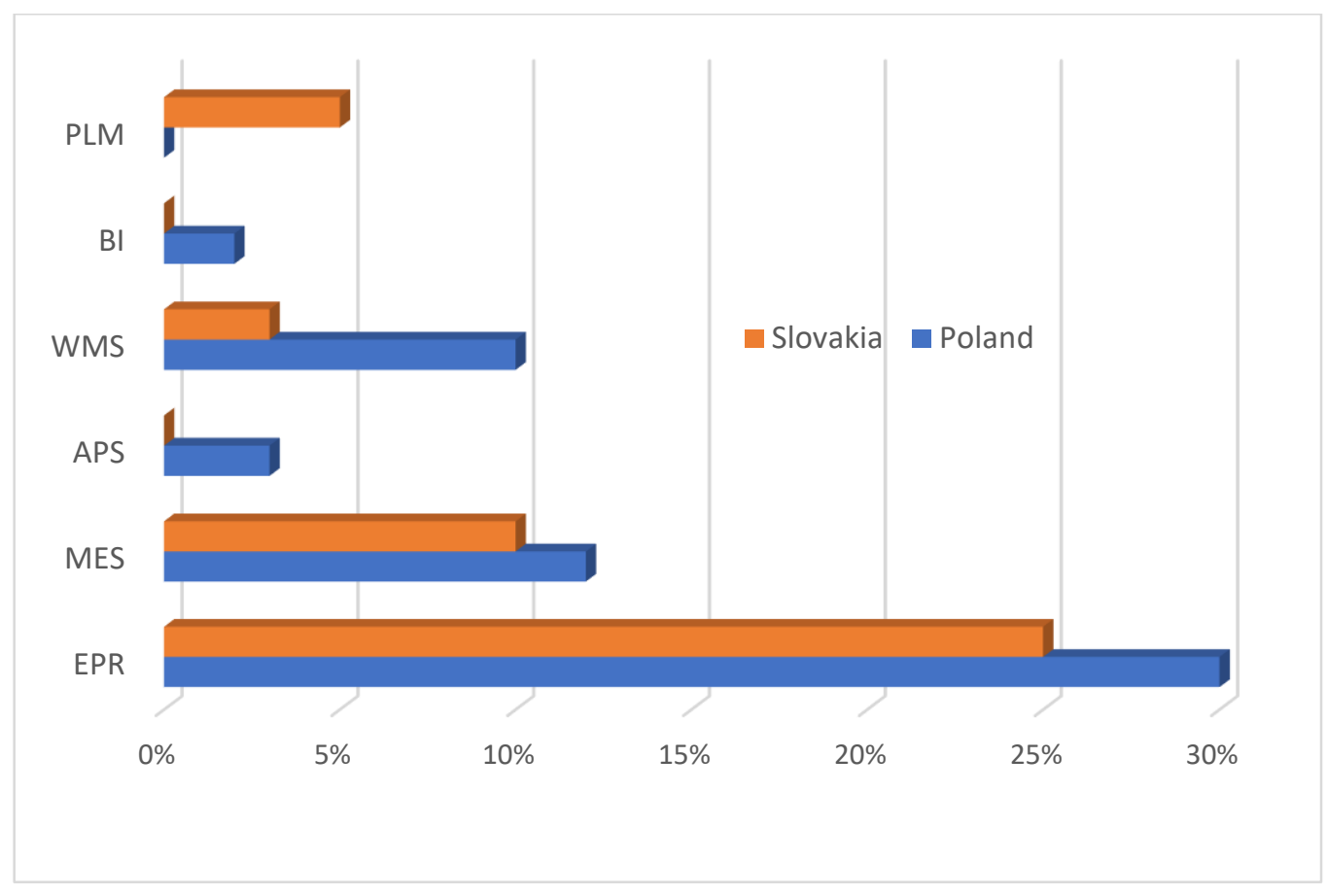

Fig. 3. The use of IT applications in the surveyed enterprises in Poland and Slovakia

In order to define the scope of application of the 4.0 industry instruments, seven main areas of application were identified:

- Calculations in the cloud

- Big Data

- Mobile devices

- Intelligent devices

- Predictive maintenance

- Robots 
- Internet of Things

Obtained answers are presented in Figure 4. As a result of the carried out analysis, it can be concluded that Slovak companies use robots and predictive maintenance of the movement to a much greater extent than Polish companies. However, Polish companies indicate the area of large amounts of data, mobile devices.

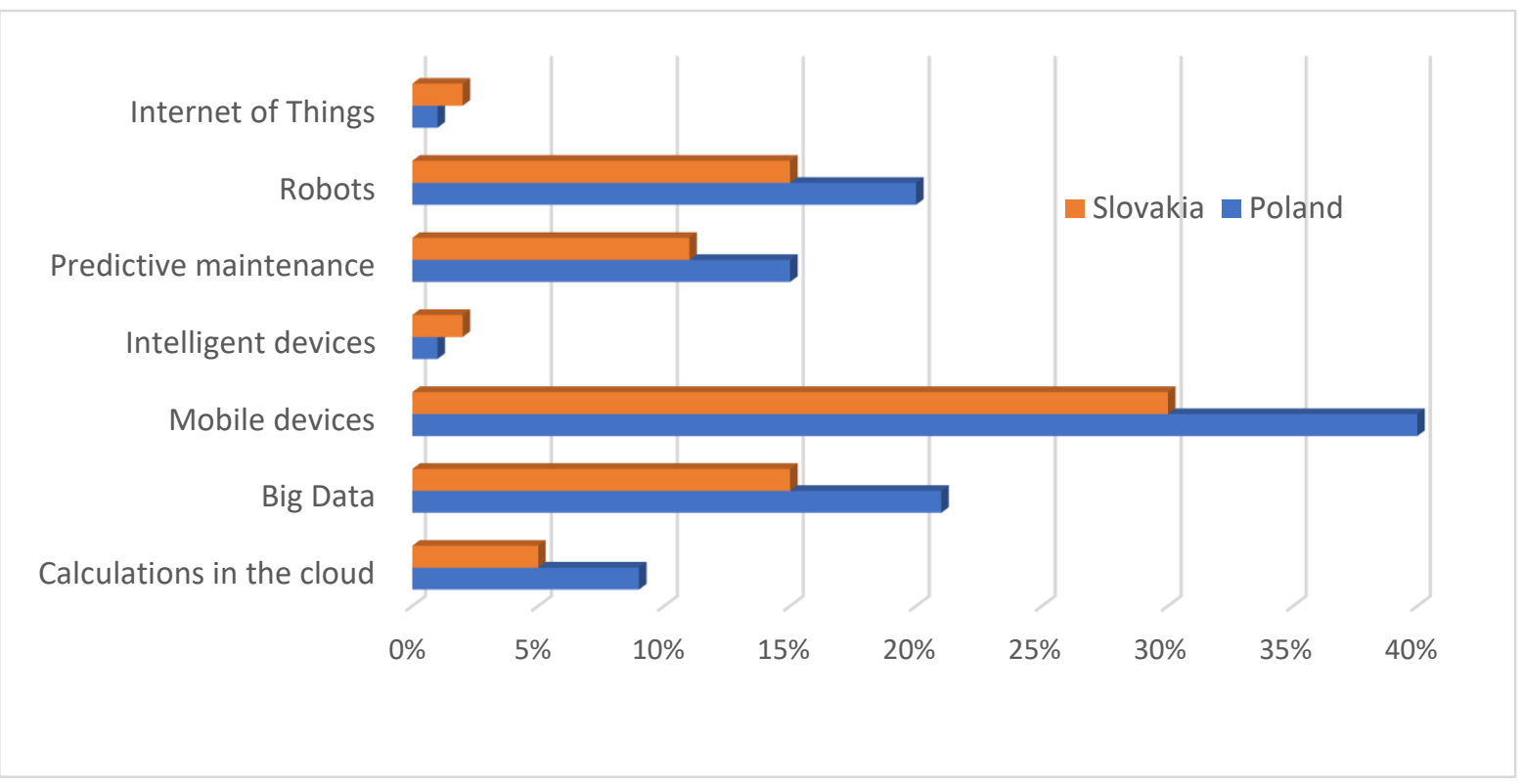

Fig. 3. Areas of use of Industry 4.0 instruments in the surveyed enterprises in Poland and Slovakia

One of the most important factors affecting the condition of enterprises are production costs. The thoughtful application of Industry 4.0 tools allows them to be reduced. To this end, many companies automate their production processes. This allows you to shorten production time, increase productivity and minimize the risk of producting defective details. An extremely important aspect of Industry 4.0 is the Internet of Things (Internet of Things, loT), which, according to research in the SME sector of the metal processing industry is at a very low level. What is puzzling is the amount of data processed at such low loT usage level is puzzling. After careful analysis, it was found that the data comes from mobile devices to which data is transmitted after having previously entered them manually. Replacing traditional methods of obtaining data with loT-based applications will allow, in the long-term, to conduct more accurate readings, save time, use human resources and machines more efficiently, and thus reduce costs. The only application of the Internet of Things is the collection of data on the state of equipment and the course of production processes. This will enable detection of the causes of changes in efficiency and sources of failure, and will allow to observe in real time the effects of decisions made.

Based on the extended interview, the most common mistakes made during the implementation of Industry 4.0 tools were defined. To the most important mistakes can be included.

- Lack of loT synchronization with the communication infrastructure and the ability to process large amounts of data, as indicated by research with communication and data processing MSP cope with the problem of data collection, 
- Lack of compatibility/synchronization with old solutions. A problem quite common connected with the evolutionary nature of the transition, it has a direct relationship with the issue of problems with raising capital,

- Excessive system complexity, generating unnecessary data,

- Lack of specialists and appropriate training.

\section{CONCLUSION}

The competitive advantage of developing countries is mainly based on low labor costs. It attracts investors and stimulates industrial production. Developed countries are already actively implementing Industry 4.0 solutions. The lack of steps taken by developing countries, ineffective or too late implementation of Industry 4.0 in the long run raises the risk of entering a vicious cycle called the "spiral of marginalization". For economies that have had growth prospects up to now, this may mean primarily the transfer of industrial production to countries implementing Industry 4.0, even if labor costs are higher there. As a consequence, production with low added value remains in the country. Competitiveness falls in comparison with other countries and the loss of the global market, which results in a further decline in employment. Properly, early response and proactive adaptation to trends can save these countries from this risk. Industry 4.0 implemented in more developed countries may threaten the production of metal products in Poland and Slovakia. The biggest threat to the SME sector in the event of failure to comply with the requirements of industry 4.0 is: loss of competitiveness due to a cost advantage that will not be as important as, for example, time of completion or quality. A big threat to SMEs is the lack of specialists who are taken over by large enterprises, and the education system is currently not adapted to the new requirements of the labor market.

The main barrier hindering the wider and systematic implementation of components of the Industry 4.0 concept is the lack of financial resources, lack of knowledge in the field of industry 4.0 and data protection. The conducted unit research does not give rise to generalizations, but it seems that this may be a problem concerning a wide spectrum of Polish and Slovak business entities. Without an effective acquisition of external financing sources, the SME sector companies may not be able to cope with the implementation of the Industry 4.0 concept.

\section{ACKNOWLEDGEMENTS}

This publication is under the project "Curriculum Development of Master's Degree Program in Industrial Engineering for Thailand Sustainable Smart Industry (MSIE4.0)" that has been funded with support from the European Commission (Project Number: 586137-EPP-1-2017-1-TH-EPPKA2-CBHE-JP).

Co-funded by the
Erasmus+ Programme
of the European Union

\section{REFERENCES}

Accelerating the Industrial Internet of Things Made in China 2025《中国制造2025》 State Council, July 7, 2015

Anttila, J., Jussila, K. (2018). Organizational learning in developing the integrated quality management. Production Engineering Archives, 18, 3-13.

Deloitte. (2015). Industry 4.0,Challenges and Solutions for the Digital Transformation and Use of Exponential Technologies; Deloitte: Swiss, Zurich, 2015. 
Fallera C., Feldmüllera D. (2015). Industry 4.0 Learning Factory for regional SMEs. Procedia CIRP 32, 2015, 88-91.

Gubbi, J., Buyya, R., Marusic, S., Palaniswami, M. (2013). Internet of Things (IoT): A vision, architectural elements, and future directions. Future Gener. Comput. Syst. 2013, 29, 1645-1660.

Hariharasudan, A., Kot, S. (2018). A scoping review on Digital English and Education 4.0 for Industry 4.0. Social Sciences, 7(11), 0-13.

Herrmann, C., Schmidt, C., Kurle, D., Blume, S., Thiede, S. (2014). Sustainability in manufacturing and factories of the future. Int. J. Precis. Eng. Manuf.-Green Technol. 2014, 1, 283-292.

Kovács, G., Kot, S. (2017). Facility layout redesign for efficiency improvement and cost reduction, Journal of Applied Mathematics and Computational Mechanics, 16(1), 63-74

Malindzak, D., Pacana, A., Pacaiova, H. (2017). An effective model for the quality of logistics and improvement of environmental protection in a cement plant, Przemys Chemiczny, 96 (9), 1958-1962

Marilungo E., Papetti A., Germani M., Peruzzini M.(2017). From PSS to CPS design: a real industrial use case toward Industry 4.0, The 9th CIRP IPSS Conference: Circular Perspectives on Product/Service-Systems, Procedia CIRP 64 (2017) 357 - 362.

Nitkiewicz, T., Ayen, Z. (2018). Identifying key criteria in development of Industrial Engineering education. MATEC Web of Conferences, 183, 04008.

Pedersen, M.R., Nalpantidis, L., Andersen, R.S., Schou, C., Bøgh, S., Krüger, V., Madsen, O. (2016). Robot skills for manufacturing: From concept to industrial deployment. Robot. Comput.-Integr. Manuf. 2016, 37, 282-291.

Pereira, A.; Romero, F. (2017), A review of the meanings and the implications of the Industry 4.0 concept. Procedia Manuf. 2017, 13, 1206-1214.

Rosak-Szyrocka, J., Blašková, M. (2016). Engineering production education in e-learning example in Poland, Production engineering Archives 12, 42-45.

Ślusarczyk, B. (2018). Industry 4.0 - Are We Ready? Polish Journal of Management Studies, 17(1), 232-248. http://doi.org/10.17512/pjms.2018.17.1.19

Thoben K.D., Wiesner S., Wuest T., (2017). Industrie 4.0 and Smart Manufacturing- A Review of Research Issues and Application Examples, International Journal of Automation and Technology 11/1, 2017. 4-16.

Wiśniewska-Sałek, A. (2018). Sustainable Development in Accordance With the Concept of Industry 4.0 on the Example of the Furniture Industry, MATEC Web of Conferences, 183, p.04005. 